\title{
HIF-1 $\alpha$ promotes ZEB1 expression and EMT in a human bladder cancer lung metastasis animal model
}

\author{
JIANNING ZHU ${ }^{1-3^{*}}$, ZHIXIN HUANG ${ }^{1 *}$, MENGZHAO ZHANG ${ }^{1}$, WEIYI WANG ${ }^{1}$, HUA LIANG $^{4}$, JIN ZENG $^{1}$, \\ KAIJIE WU ${ }^{1}$, XINYANG WANG ${ }^{1}$, JER-TSONG HSIEH ${ }^{5}$, PENG GUO $^{1}$ and JINHAI FAN ${ }^{1}$ \\ ${ }^{1}$ Department of Urology, The First Affiliated Hospital of Xi'an Jiaotong University, Xi'an, Shaanxi 710061; \\ ${ }^{2}$ Department of Urology, The Central Hospital of Wuhan; ${ }^{3}$ Department of Urology, Tongji Medical College, \\ Huazhong University of Science and Technology, Wuhan, Hubei 430014; ${ }^{4}$ Department of Pathology, \\ The First Affiliated Hospital of Xi'an Jiaotong University, Xi'an, Shaanxi 710061, P.R. China; \\ ${ }^{5}$ Department of Urology, University of Texas Southwestern Medical Center, Dallas, TX 75390, USA
}

Received October 5, 2016; Accepted October 24, 2017

DOI: $10.3892 / \mathrm{ol} .2018 .7764$

\begin{abstract}
Lung is one of the most common sites for bladder cancer to metastasize. Although the involvement of the epithelial-to-mesenchymal transition (EMT) in bladder cancer progression has been established, the mechanism of EMT induction remains unclear. In order to investigate this, T24-parental (P) and T24-lung (L) bladder cancer cells were obtained from primary tumors and lung metastatic sites of an animal model with orthotopic spontaneous metastatic bladder cancer, according to a protocol previously described. Compared with T24-P cells, mesenchymal-like T24-L cells exhibited an increased ability in tumor invasion and metastasis, as well as an increased expression of hypoxia-inducible factor (HIF)- $1 \alpha$, zinc finger E-box-binding homeobox 1 (ZEB1), vimentin and $\mathrm{N}$-cadherin and lower level of cytokeratin 18 were observed. Mechanistically, it was identified that HIF-1 $\alpha$ increases ZEB1 expression and subsequently regulates the expression of EMT-related genes in both HIF-1 $\alpha$ knocking down by siRNA and gain-in HIF-1 $\alpha$ by hypoxia culture cell models. In addition, the expression of HIF-1 $\alpha$ and ZEB1 in bladder cancer tissues were increased compared with normal bladder epithelial tissues, as well as significantly increased in the high-grade, invasive and metastatic bladder cancer tissues compared with low-grade, superficial and non-metastatic bladder cancer tissues by using immune-histochemical staining assay. Notably, the protein level of HIF-1 $\alpha$ was positively associated with that of ZEB1 in bladder cancer tissues. Results from the
\end{abstract}

Correspondence to: Dr Jinhai Fan, Department of Urology, The First Affiliated Hospital of Xi'an Jiaotong University, 277 Yanta West Road, Xi'an, Shaanxi 710061, P.R. China

E-mail: jinhaif029@126.com

*Contributed equally

Key words: bladder cancer, epithelial-to-mesenchymal transition, metastasis present study indicate that HIF-1 $\alpha$ promotes ZEB1 expression and EMT in the T24-L human bladder cancer lung metastasis animal model, suggesting that HIF-1 $\alpha$ serves an important function in the metastasis of bladder cancer, and HIF-1 $\alpha$ and ZEB1 may be potential targets for inhibiting bladder metastasis in the future.

\section{Introduction}

Urothelial carcinoma of the bladder (UCB) is the fifth most common malignancy worldwide (1). In total, $70-80 \%$ of patients diagnosed with well-differentiated or moderately-differentiated non-muscle invasive bladder cancer (2). Despite treatment, cancer recurs in $60-70 \%$ of patients, of which, 10-30\% eventually develop muscle-invasive bladder cancer or metastatic bladder cancer. The lung is one of the most common metastatic sites and is associated with a high frequency of recurrence and mortality, which contributes to a poor prognosis for patients $(3,4)$. Therefore, to develop better therapeutic strategies and decrease the morbidity and mortality associated with bladder cancer, it is imperative to clarify the mechanism of bladder cancer invasion and metastasis.

Clinical investigations have indicated hypoxia to be a common feature of most solid tumors (5), owing to rapid proliferation of cancer cells and/or compression of tumor blood vessels. As a cancer progresses, cancer cells acquire the ability to adapt to hypoxic environments while also resist to apoptosis, increase angiogenesis, enhance the invasive and metastatic potential which makes them more aggressive. A previous study suggests that one of the key factors regulating the response to hypoxia is the heterodimer hypoxia-inducible factor-1 (HIF-1) (6). Under hypoxic conditions, the alpha subunit is not destroyed, and will activate transcription more than 100 gene products that take part in the tumor aggressiveness (6). Its expression is associated to an increased metastatic potential that has been demonstrated in both animal models and human tumors by promotes a perpetual epithelial to mesenchymal transition (EMT) (7).

The transcription factor Zinc-finger E-box-binding homeobox 1 (ZEB1) is a known driver of EMT, and our previous 
reports (8) confirmed that ZEB1 is an important regulatory factor of bladder cancer invasion and metastasis in vitro and in vivo. Furthermore, ZEB1 high expression is closely associated with markers associated with invasion and metastasis in clinical tumor specimens (9). However, little is known about the association between HIF-1 $\alpha$ and ZEB1 protein in bladder cancer, and whether there is an interaction between HIF-1 $\alpha$ and ZEB1 in the process of invasion and metastasis of bladder cancer.

To address these issues, an orthotopic animal model was established by injecting human bladder cancerT24-tumorigenic (T24-t) cells into a mouse bladder. Subsequently, the primary tumor and lung metastases were excised and plated on tissue culture dishes with $\mathrm{G} 418(400 \mu \mathrm{g} / \mathrm{ml})$ to derive the sublines T24-parental (T24-P) and T24-t-lung (T24-L), which were outlined in our previous study $(10,11)$. In the present study, the previously described sublines T24-P and T24-L, were used to investigate the role of downstream gene regulation of HIF-1 $\alpha$ and EMT by mimicking human bladder cancer metastasis (10). In addition, the molecular mechanisms of the lung metastasis of bladder cancer were explored, focusing on the effect of HIF-1 $\alpha$ expression changes in bladder cancer cells on ZEB1 expression, and the invasion and metastasis of bladder cancer cells.

\section{Materials and methods}

Human tissue specimens. All the paraformaldehyde-fixed and paraffin-embedded primary bladder cancer tissues $(n=79)$ and adjacent histologically normal tissues $(n=11)$ were obtained from the Department of Urology, The First Affiliated Hospital of Xi'an Jiaotong University, (Xi'an, China). All the tissues were either obtained from transurethral resection of bladder tumor (TURBT) or Radical cystectomy between 2,006.1 and 2,011.9. The histopathology of the specimens was examined and classified by pathologists of Medical School, Xi'an Jiaotong University. Sixty-six patients were men and thirteen were women. Mean patient age was 63 years (range, 35-82 years). Bladder carcinomas were staged according to the tumor-node-metastasis system based on the International Union against Cancer (12). Genitourinary pathologists determined tumor stage as: Ta $(n=1)$; T1 $(n=41)$; T2 $(n=17)$; T3 $(n=17) ; \mathrm{T} 4(\mathrm{n}=3)$, and according to World Health Organization (1973) standard for pathological grade (13): grade I $(n=26)$, grade II $(n=32)$, grade III $(n=21)$. This study was approved by the Committee for the Protection of Human Subjects of the First Affiliated Hospital of Xi'an Jiaotong University, and informed consent was obtained from all patients.

Reagents and antibodies. A HIF-1 $\alpha$ siRNA transfection kit was purchased from Shanghai GenePharma Co, Ltd (Shanghai, China). Matrigel was purchased from BD Transduction Laboratories (Franklin Lakes, NJ, USA). Antibodies used for western blot were as follows: mouse monoclonal antibodies to cytokeratin 18 (1:1,000; cat. no. 4546; Cell Signaling Technology, Beverly, MA, USA), goat polyclonal antibody to Vimentin (1:500; cat. no. sc-7557; Santa Cruz Biotechnology, Santa Cruz, CA, USA), GAPDH (1:1,2000; cat. no. KC-5G4; Kang Chen Bio-technology, Shanghai, China), rabbit polyclonal antibody to N-cadherin (1:1,000; cat. no. 13116; Cell
Signaling Technology), HIF-1 $\alpha$ (1:1,000; cat. no. ab113642; Abcam, Cambridge, UK) and rabbit monoclonal antibody to ZEB1 (1:1,000; cat. no. 3396; Cell Signaling Technology). Rabbit polyclonal antibody to HIF-1 $\alpha$ for immunohistochemical staining (1:500; cat. no. 04-006; Millipore Corporation, Billerica, MA, USA), rabbit monoclonal antibody to ZEB1 for immunohistochemical staining (1:500; cat. no. A301-922A; Bethyl Laboratories, Montgomery, TX, USA) were used.

Immunohistochemical (IHC) staining. The standard two-step Envision method of IHC staining was used to assess the expression of HIF- $1 \alpha$ and ZEB1. Briefly, $5 \mu \mathrm{m}$ sections were deparaffinized, rehydrated and subjected to antigen retrieval in citrate buffer $(10 \mathrm{mM}, \mathrm{pH}$ 6.0) for $5 \mathrm{~min}$ at high temperature $\left(121^{\circ} \mathrm{C}\right)$, and then endogenous peroxidase and alkaline phosphatase activity were and blocked by incubating in $0.3 \% \mathrm{H}_{2} \mathrm{O}_{2}$ for $30 \mathrm{~min}$. Slides were then incubated overnight at $4^{\circ} \mathrm{C}$ with IHC-specific HIF-1 $\alpha$ and ZEB1 antibodies (dilution, 1:200) in a moist chamber. Following a wash with PBS, the slides were incubated with horseradish peroxidase-labelled anti-rabbit (dilution, 1:100; cat. no. K4002; Dako; Agilent Technologies, Inc.) for $30 \mathrm{~min}$ at room temperature. Rinsed with PBS, signals were detected by adding substrate hydrogen peroxide using diaminobenzidine as a chromogen followed by hematoxylin counterstaining, dehydrated, air-dried, and mounted. Negative control slices were prepared by omitting the primary antibody. HIF-1 $\alpha$ and ZEB1 expression in human TCC tumors was semiquantitatively evaluated according to the intensity of the staining $(0,1+, 2+$ and $3+)$ and the percentage of positive cells [0 ( $\leq 10 \%), 1(10-25 \%), 2(25-50 \%), 3(50-75 \%)$ and $4(\geq 75 \%)]$. The staining result was considered higher expression when intensity was $2+$ or $3+$ and the percentage category was 2-4, and lower expression when intensity was 0 or $1+$, or if intensity was $>1$ and the percentage category was 0 or 1 . All sections were evaluated blindly by 2 of the authors.

Cell line and cell culture. All components for cell culture were purchased from Invitrogen (Thermo Fisher Scientific, Inc., Waltham, MA, USA). T24-parental (P) and T24-lung (L) bladder cancer cells were obtained from primary tumors and lung metastases according to a protocol previously described $(10,11)$. Cells were maintained in Dulbecco's modified Eagle's medium (DMEM; Gibco; Thermo Fisher Scientific, Inc.) supplemented with $10 \%$ fetal bovine serum (FBS; Invitrogen; Thermo Fisher Scientific Inc.) and $400 \mathrm{mg} / 1$ G418 in a humidified incubator with $5 \% \mathrm{CO}_{2}, 95 \%$ air at $37^{\circ} \mathrm{C}$. While, for mimicking the hypoxia conditions, the cells were cultured in the atmosphere with $1 \% \mathrm{O} 2$ and $99 \% \mathrm{~N} 2$ in $37^{\circ} \mathrm{C}(10,11)$.

Small interfering RNA (siRNA) transfection. The sequence of siRNA for HIF-1 $\alpha$ was as follows: Sense 5'-CCAGCA GACUCAAAUACAATT-3', antisense 5'-UUGUAUUUG AGUCUGCUGGTT-3' (Shanghai GenePharma, Shanghai, China). A total of $5 \times 10^{5}$ cells were seeded in a 6 -well plate and grown to $70-80 \%$ confluence prior to transfection. Cells were transfected, according to the manufacturer's protocol, with oligonucleotide duplexes $(200 \mathrm{nM})$ premixed with Oligofectamine (Invitrogen; Thermo Fisher Scientific, Inc.) in Opti-MEM-I (Invitrogen; Thermo Fisher Scientific, Inc.) 
for $4 \mathrm{~h}$. Cells were treated with oligofectamine and scrambled siRNA served as a negative control (NC-siRNA sense, 5'-UUC UCCGAACGUGUCACGUTT-3' and anti-sense, 5'-ACGUGA CACGUUCGGAGAATT-3'; Dharmacon, Lafayette, CO, USA). Transfection studies were performed in duplicates according to the manufacturer's protocol.

RNA extraction and quantitative RT-PCR. Total cellular RNA was extracted using the Highly Pure RNA Isolation kit (Invitrogen; Thermo Fisher Scientific, Inc.) according to the protocol provided by the manufacturer, and was quantified by absorbance at $260 \mathrm{~nm}$. Total RNA $(2 \mu \mathrm{g})$ was reverse transcribed using a Revert Aid ${ }^{\mathrm{TM}}$ First Strand cDNA Synthesis kit (Fermentas; Thermo Fisher Scientific, Inc.) according to the manufacturer's protocol. Primers for the amplification of HIF- $1 \alpha$ and ZEB1 were constructed with the following sequences: HIF-1 $\alpha$ forward, 5'-TCAAAGTCGGACAGC-CTC A-3', reverse, 5'-CCCTGCAGTAGGTTTCT-GCT-3', 460 bp product; ZEB1 forward, 5'-TTCAAACCCATAGTGGTT GCT-3', reverse, 5'-TGGGAGATACCAAACCAACTG-3', $151 \mathrm{bp}$ product; $\beta$-actin forward, 5'-ATCATGTTTGAGACC TTCAACA-3', reverse, 5'-CATCTCTTGCTCGAAGTCCA-3', 318 bp product.

For qPCR, the SYBR Premix Ex Taq ${ }^{\mathrm{TM}}$ II system (Takara Biotechnology Co., Ltd., Dalian, China) was used with the CFX96TM Real-time system (Bio-Rad Laboratories, Inc., Hercules, CA, USA). The reaction mix tubes contained SYBR Premix Ex Taq II (12.5 $\mu \mathrm{l}), 1 \mu \mathrm{l}$ primer $(10 \mu \mathrm{M}$, ), $200 \mathrm{ng}$ cDNA and $9.5 \mu \mathrm{lddH_{2 }}$ O. There was one cycle of pre-degeneration at $95^{\circ} \mathrm{C}$ for $30 \mathrm{sec}$, then 35 repeats of $95^{\circ} \mathrm{C}$ for $5 \mathrm{sec}$ followed by $60^{\circ} \mathrm{C}$ for $30 \mathrm{sec}$, then a final stage of $95^{\circ} \mathrm{C}$ for $15 \mathrm{sec}$ followed by $60^{\circ} \mathrm{C}$ for $30 \mathrm{sec}$, and $15 \mathrm{sec}$ at $95^{\circ} \mathrm{C}$. $\beta$-actin was used as an internal control. All experiments were repeated at least twice in duplicate.

Invasion and migration assays. The invasion and migration capability of cells in vitro was determined using a Boyden chamber assay. For the invasion assay, $50 \mu \mathrm{l}$ of Matrigel was applied to $8 \mu \mathrm{m}$ pore polycarbonate membrane filters (BD Biosciences, San Jose, CA, USA) in a 24-well plate, and allowed to solidify overnight. Then, $5 \times 10^{4}$ cells, detached using trypsin-EDTA and resuspended in $200 \mu$ l FBS-free DMEM were added to the upper chamber, and $800 \mu 1$ FBS-free DMEM was added to the lower chamber. Subsequent to incubating the plates at $37^{\circ} \mathrm{C}$ in $5 \% \mathrm{CO}_{2}$ for $24 \mathrm{~h}$, cells on top of the membrane were scraped away using a cotton swab. Cells at the bottom surface of the membrane were fixed with $4 \%$ paraformaldehyde for $10 \mathrm{~min}$, stained with crystal violet solution $(0.01 \%$ in the ethanol) for $15 \mathrm{~min}$ at room temperature, then washed three times with PBS ( $\mathrm{pH} 7.4)$. The cells were counted using an inverted microscope; 5 fields of view were randomly selected at x100 magnification, and the mean number of cells was determined. For determining cell migration, the Boyden chamber assay was performed as described above, without Matrigel. Presented data are representative of three individual wells.

Wound healing assay. Cells were cultured to a monolayer of $100 \%$ confluence in a 6 -well plate and washed three times with PBS ( $\mathrm{pH} 7.4$ ) to remove residual FBS. Subsequent to incubating the cells at $37^{\circ} \mathrm{C}$ in $5 \% \mathrm{CO}_{2}$ for $12 \mathrm{~h}$ with $\mathrm{FBS}$-free DMEM, the plate was scratched to remove a 400-450 $\mu \mathrm{m}$ strip of cells across the well with a standard $200 \mu$ l pipette tip. Wounded monolayers were washed twice with PBS to remove non-adherent cells, and the cells were incubated at $37^{\circ} \mathrm{C}$ in $5 \% \mathrm{CO}_{2}$. The width of the scratches was photographed and measured at 0,6 and $12 \mathrm{~h}$ after scratching. Presented data are representative of three individual wells.

Protein extraction and western blot analysis. Cells were harvested at $70-80 \%$ confluence and washed with $4^{\circ} \mathrm{C}$ PBS three times. Total cellular protein lysates were prepared with radio immunoprecipitation assay buffer [50 mM Tris ( $\mathrm{pH} 8.0)$, $150 \mathrm{mM} \mathrm{NaCl}, 0.1 \% \mathrm{SDS}, 1 \% \mathrm{NP} 40$ and $0.5 \%$ sodium deoxycholate] containing proteinase inhibitors $1 \%$ cocktail and $1 \mathrm{mM}$ PMSF, (Sigma Aldrich; Merck KGaA, Darmstadt, Germany). A total of 20-40 $\mu \mathrm{g}$ of protein (Pierce bicinchoninic acid assay protein assay kit; cat. no. 23225; Thermo Fisher Scientific, Inc.) was separated by SDS-PAGE (10\% gel) and transferred to nitrocellulose membranes. Following blocking at room temperature for $1 \mathrm{~h}$ with $5 \%$ skimmed milk in TBS ( $\mathrm{pH} 7.6$ ), the membranes were incubated with primary antibodies (HIF-1 $\alpha$, ZEB1 and N-Cadherin, 1:1,000; CK18, Vimentin, 1:300; GAPDH, 1:15,000) at $4^{\circ} \mathrm{C}$ overnight, then washed with TBST with Tween-20 (pH 7.6). Membranes were incubated with goat anti-rabbit (1:5,000; cat. no. A0545; Sigma Aldrich; Merck KGaA) or anti-mouse secondary antibody (1:30,000; cat. no. A5278; Sigma Aldrich; Merck $\mathrm{KGaA}$ ) coupled to the first antibody at room temperature in the dark for $1 \mathrm{~h}$, followed by washing as above in the dark, drying with neutral absorbent paper and scanning by Odyssey detection system (LI-COR Biosciences, Lincoln, NE, USA). MG-132 (Sigma Aldrich, Merck KGaA) was used to inhibit proteasome-dependent degradation if necessary $(10 \mu \mathrm{M}, 4 \mathrm{~h}$ prior to protein harvesting). Loading differences were normalized using a monoclonal GAPDH antibody.

Statistical analysis. All statistical analyses were performed using SPSS 19.0 (IBM Corp., Armonk, NY, USA). Quantitative data are presented as the mean \pm standard deviation from $\geq 3$ independent experiments. The statistical significance of differences among multiple groups was one-way analysis of variance followed by Bonferroni's multiple comparisons test. When the comparison involved only 2 groups, a 2-sided Student's t-test was used. IHC statistical analysis was performed with the $\chi^{2}$ test. The analysis of HIF- $1 \alpha$ and ZEB1 association was performed using Spearman's correlation analysis. $\mathrm{P}<0.05$ was considered to indicate a statistically significant difference.

\section{Results}

Expression of HIF-1 $\alpha$ and ZEBI in human bladder cancer tissues and normal bladder tissues. To investigate the association between the expression of HIF-1 $\alpha$ and ZEB1 in bladder carcinoma, IHC staining for HIF-1 $\alpha$ and ZEB1 was performed on 79 UCB tissues and 11 normal bladder epithelial control tissues. The staining results (Fig. 1) indicated that HIF-1 $\alpha$ and ZEB1 expression occurred in the cytoplasm and nucleolus in bladder cancer tissues. The expression of HIF-1 $\alpha(\mathrm{P}=0.005)$ and ZEB1 $(\mathrm{P}=0.007)$ in UCB tissues 
A

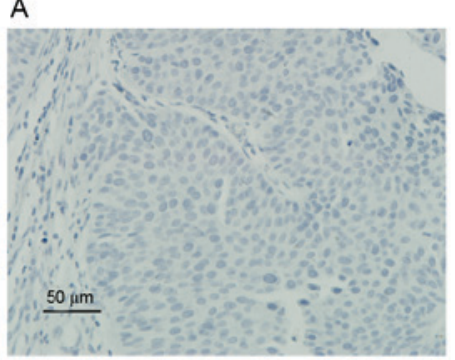

D

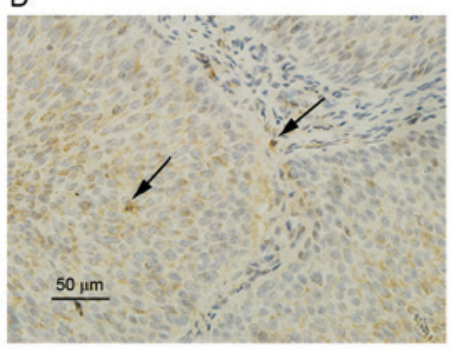

G

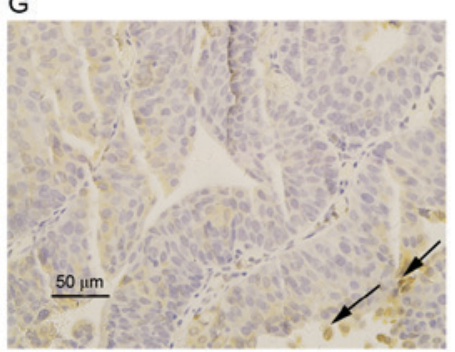

B

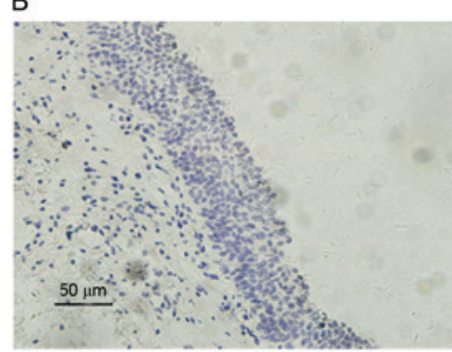

E

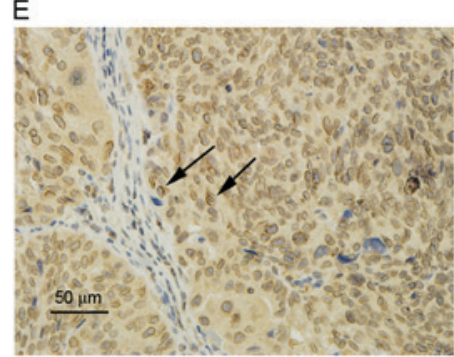

$\mathrm{H}$

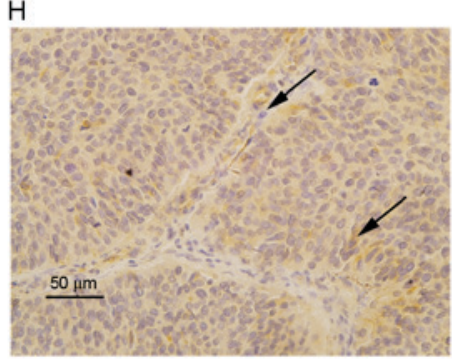

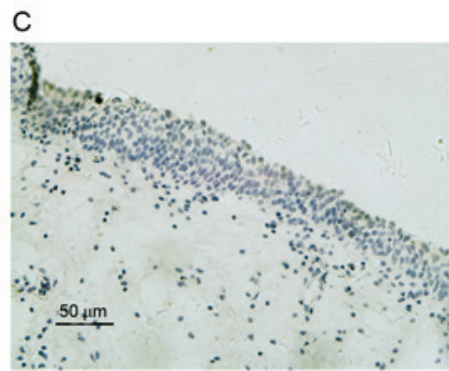

$F$

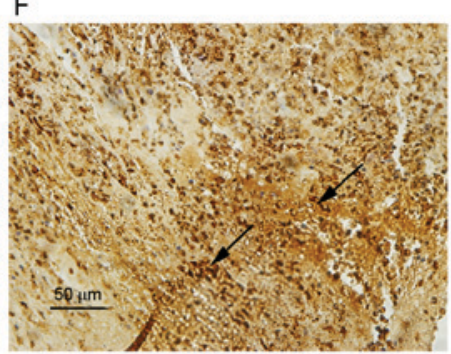

I

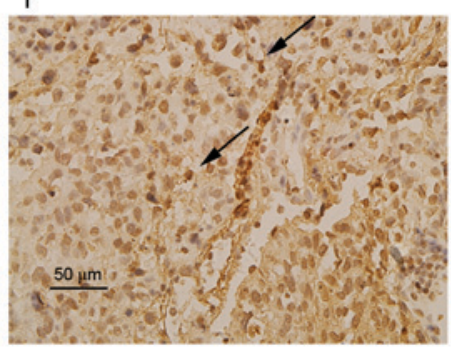

Figure 1. Representative immunohistochemical staining images of (A) bladder cancer negative staining control; (B) normal epithelium stained for HIF-1 $\alpha$; (C) normal epithelium stained for ZEB1; grade (D) G1, (E) G2 and (F) G3 tumor tissue stained for HIF-1 $\alpha$; grade (G) G1, (H) G2 and (I) G3 tumor tissue stained for ZEB1. Certain positively stained cells are indicated by black arrows. Scale bar, $50 \mu \mathrm{m}$. HIF-1 $\alpha$, hypoxia inducible factor-1 $\alpha$; ZEB1, zinc-finger E-box binding homeobox 1 .

was significantly higher than in normal bladder epithelium (Table I). The expression score and rate of HIF-1 $\alpha$ and ZEB1 were also significantly higher in the high-grade, invasive and metastatic UCB than in low-grade, superficial and non-metastatic UCB $(\mathrm{P}<0.05)$. However, a Mann-Whitney $\mathrm{U}$ test identified no significant differences $(\mathrm{P}>0.05)$ in HIF-1 $\alpha$ and ZEB1 expression levels according to age ( $<60$ and $\geq 60$ years) and sex (Table II).

In the 79 UCB tissues, the positive expression rate of HIF-1 $\alpha$ was $59.49 \%$ (47/79), and that of ZEB1 was $49.37 \%$ (36/79). The positive expression rate of ZEB1 was 76.6\% (36/47) in HIF-1 $\alpha$ positive expression group. In the HIF-1 $\alpha$-negative group, the ZEB1 positive expression rate was 9.38\% (3/32). Spearman's rank correlation analysis indicated a significant positive association between the expression of HIF-1 $\alpha$ and ZEB1 ( $\mathrm{r}=0.337$, $\mathrm{P}<0.05$, Table II).

HIF-1 $\alpha$ promotes bladder cancer cell migration and invasion in vitro. It was reported in our previous study that the T24-P and T24-L sublines had a similar growth rate; however, the growth rate of orthotopic and metastatic xenograft bladder tumors of T24-L cells was slightly higher than that of T24-P cells. In addition, the incidences of distant metastasis observed in the T24-P and T24-L group were 9 and 36\%, respectively.

HIF-1 $\alpha$ is known to serve an important role in tumor metastasis. To identify the roles of HIF-1 $\alpha$ in bladder cancer invasion and metastasis, the expression of HIF-1 $\alpha$ in T24-P and T24-L cells was examined; it was identified that HIF-1 $\alpha$ mRNA level was higher in T24-L cells than that in T24-P cells using an RT-qPCR assay (Fig. 2A). In addition, to further identify the function of HIF-1 $\alpha$ in T24-L cells, HIF-1 $\alpha$ expression was knocked down by transfecting HIF-1 $\alpha$ and scrambled siRNA into T24-L cells. As demonstrated in Fig. 2A, the HIF-1 $\alpha$ expression level was significantly reduced by transfection with siRNA against HIF-1 $\alpha$ compared with the negative control group in T24-L cells, as determined by RT-qPCR analysis $(\mathrm{P}<0.001)$.

To determine whether HIF-1 $\alpha$ knockdown affects the migration and/or invasion of bladder cancer cell lines, wound-healing and transwell assays were performed. It was identified that the migration and invasion ability of T24-L cells were greater than T24-P cells (Fig. 2B, C and D; P<0.001); in addition, HIF-1 $\alpha$ knockdown by siRNA significantly reduced the cell motility and invasion of T24-L cells $(\mathrm{P}<0.001)$. These results indicated that $\mathrm{HIF}-1 \alpha$ promoted the migration and invasion of bladder cancer cells.

HIF-1 $\alpha$ increases ZEBI expression and promotes EMT in bladder cancer cells. EMT may be a crucial step in the initiation of the metastatic spread of tumor cells into distal organs (7); ZEB1 may be a key driver of bladder cancer invasion and metastasis (14). Therefore, it was examined whether 
Table I. HIF-1 $\alpha$ and ZEB1 expression in bladder tumor and normal tissues as determined with immunohistochemistry analysis.

\begin{tabular}{|c|c|c|c|c|c|c|}
\hline \multirow{2}{*}{$\begin{array}{l}\text { Tissue } \\
\text { type }\end{array}$} & \multicolumn{3}{|c|}{ HIF- $1 \alpha$ expression score } & \multicolumn{3}{|c|}{ ZEB1 expression score } \\
\hline & Mean & SD & P-value & Mean & SD & P-value \\
\hline Tumor & 3.75 & 0.44 & 0.005 & 2.81 & 0.39 & 0.007 \\
\hline Normal & 2.02 & 0.81 & & 2.01 & 0.79 & \\
\hline
\end{tabular}

HIF-1 $\alpha$, hypoxia inducible factor- $1 \alpha$; ZEB1, zinc-finger E-box-binding homeobox 1; SD, standard deviation.

the expression of HIF-1 $\alpha$ modulates ZEB1 expression or the process of EMT in bladder cancer cells. As demonstrated in Fig. 3A, ZEB1 mRNA expression in T24-L cells was significantly higher than that in T24-P cells, as detected by RT-qPCR, and significantly reduced in T24-L cells transfected with HIF-1 $\alpha$ siRNA. Furthermore, as determined by western blot analysis, HIF-1 $\alpha$, ZEB1, N-cadherin and vimentin protein expression was higher in T24-L cells than in T24-P cells, whereas cytokeratin-18 protein level was lower in T24-L cells. In T24-L cells transfected with HIF-1 $\alpha$ siRNA, HIF-1 $\alpha$, ZEB1, $\mathrm{N}$-cadherin and vimentin protein was downregulated whereas the expression of cytokeratin-18 was upregulated (Fig. 3B). These results indicate that HIF-1 $\alpha$ expression increased the expression of ZEB1 and promoted the process of EMT in bladder cancer cells.

It was then determined whether the induction of HIF-1 $\alpha$ expression by hypoxia also regulated ZEB1 expression. As displayed in Fig. 4, hypoxia significantly increased the mRNA level of HIF-1 $\alpha$ and ZEB1 in T24-P cells, as detected by RT-qPCR. Furthermore, hypoxia increased the protein expression of HIF-1 $\alpha$, ZEB1, N-cadherin and vimentin in T24-P cells, whereas cytokeratin18 protein expression was reduced, as identified by western blot analysis. These results confirm that HIF-1 $\alpha$ can increase the expression of ZEB1 and suggest that hypoxia promotes cell migration and invasion through HIF-1 $\alpha$ and ZEB1 expression in bladder cancer.

\section{Discussion}

Owing to incomplete blood vessel networks and the imbalance between proliferation and angiogenesis, hypoxia is a common feature of the microenvironment in various solid tumors, including bladder cancer $(15,16)$. Hypoxia serves a critical role in various cellular and physiologic events, including cell proliferation, survival, angiogenesis (17), immune-surveillance, metabolism, and tumor invasion and metastasis, and it is often associated with a poor prognosis (18). Investigating the biology of tumor cells in hypoxic conditions may be important for improving therapeutic efficacy and for eradication of cancer. Hypoxia activates relevant gene expression through HIFs, transcription factors from a family that includes HIF-1, HIF-2 and HIF-3. HIF is a heterodimer composed of an alpha and a beta subunit, in which the HIF-1 $\alpha$ protein is a master regulator of the hypoxic response in bladder urothelial carcinomas (6). HIF-1 $\alpha$ may be associated with clinicopathological parameters with prognostic value, including tumor stage, grade, proliferation index and microvessel density (19). Our previous study provided novel insights into the mechanism of HIF-1 $\alpha /$ matrix metalloproteinase- 1 in the process of distant metastasis of bladder cancer, offering a potential therapeutic target for metastatic bladder cancer therapy (10). In the present study, it was identified that HIF-1 $\alpha$ promotes cell migration and cell invasion, and that hypoxia may induce EMT through HIF-1 $\alpha$ in bladder cancer, suggesting that HIF-1 $\alpha$ serves an important role in bladder cancer metastasis.

As a potent suppressor of epithelial marker, transcription factor ZEB1 is one of the key inducers of EMT; its expression promotes the tumorigenesis and metastasis of various types of carcinoma (20). Our previous study (21) revealed a novel mechanism facilitating metastatic bladder cancer cell re-colonization into bone, in which phosphoinositide 3-kinase/Akt targeted glycogen synthase kinase $3 \beta / \beta$-catenin and regulated the expression of ZEB1. Furthermore, the results provided a molecular and clinicopathological basis for the role of ZEB1 in bladder cancer invasion and metastasis. Therefore, ZEB1 could be a potential prognostic marker and a drug target for muscle-invasive or metastatic bladder cancer (21).

It was previously reported that dysregulated HIF-1 activity resulting from VHL loss of function in RCC4 cells induces the expression of multiple known repressors of CDH1 (ZEB1) gene transcription directly or indirectly, so as to promote tumor progression, invasion and metastasis (17). However, there is limited data regarding the association between HIF-1 $\alpha$ and $\mathrm{ZEB} 1$ protein in bladder cancer tissue, and whether there is interaction between HIF- $1 \alpha$ and ZEB1 in the process of invasion and metastasis of bladder cancer. In the present study, the expression of HIF-1 $\alpha$ and ZEB1 in bladder transitional cell carcinoma tissues were significantly increased compared with normal bladder epithelium tissues. Furthermore, the expression score and rate of both HIF-1 $\alpha$ and ZEB1 were significantly higher in the high-grade, invasive and metastatic bladder cancer compared with low-grade, superficial and non-metastatic bladder cancer $(\mathrm{P}<0.05)$ and expression of both proteins were positively associated with each other in bladder carcinoma tissues. To our knowledge, this is the first study involved in the association between HIF-1 $\alpha$ and ZEB1 protein expression in bladder cancer tissue.

To further investigate the interaction between HIF-1 $\alpha$ and ZEB1 in the process of invasion and metastasis of bladder cancer, a novel model of TCC metastasis was adopted, consisting of two isogenetic T24-t sublines, T24-P and T24-L we adopt a novel model of bladder cancer metastasis consisting of two isogenetic T24-t sublines, designated T24-P and T24-L, generated through successive in vivo passaging and in vitro subculture (11).

The sublines were previously demonstrated to exhibit a similar in vitro growth rate, and share several of the same numerical and structural abnormalities of karyotypes. Cytogenetic evaluation of T24-P cells (having the same molecular features of bladder cancer in situ) and T24-L cells (having the same molecular features with cells of bladder cancer lung metastasis) revealed that these cell lines are indeed associated; however, exhibit specific cytogenetic abnormalities $(10,11)$. For example, T24-L cells exhibited more invasive and metastatic 
Table II. Association between the IHC expression of HIF-1 $\alpha$ and ZEB1 with clinical characteristics.

\begin{tabular}{|c|c|c|c|c|c|c|c|c|c|}
\hline \multirow[b]{2}{*}{ Characteristic } & \multirow[b]{2}{*}{$\mathrm{n}$} & \multicolumn{4}{|c|}{ HIF-1 $\alpha$ expression } & \multicolumn{4}{|c|}{ ZEB1 expression } \\
\hline & & $(-), \mathrm{n}$ & $(+), \mathrm{n}$ & $R$ value & P-value & $(-), \mathrm{n}$ & $(+), \mathrm{n}$ & $R$ value & P-value \\
\hline Age & & & & -0.143 & 0.825 & & & -0.117 & 0.753 \\
\hline$\leq 60$ & 31 & 14 & 17 & & & 16 & 15 & & \\
\hline$>60$ & 48 & 18 & 30 & & & 24 & 24 & & \\
\hline Sex & & & & -0.132 & 0.439 & & & 0.115 & 0.557 \\
\hline Male & 66 & 26 & 40 & & & 36 & 30 & & \\
\hline Female & 13 & 6 & 7 & & & 4 & 9 & & \\
\hline Grade & & & & 0.462 & 0.003 & & & 0.381 & 0.004 \\
\hline G1 & 26 & 21 & 5 & & & 22 & 4 & & \\
\hline G2-3 & 53 & 11 & 42 & & & 18 & 35 & & \\
\hline Stage & & & & 0.387 & 0.002 & & & 0.452 & $<0.001$ \\
\hline Ta-1 & 42 & 30 & 12 & & & 32 & 10 & & \\
\hline $\mathrm{T} 2-4$ & 37 & 2 & 35 & & & 8 & 29 & & \\
\hline Lymphatic metastasis & & & & 0.213 & $<0.001$ & & & 0.314 & 0.003 \\
\hline Yes & 10 & 0 & 10 & & & 1 & 9 & & \\
\hline No & 69 & 32 & 37 & & & 39 & 30 & & \\
\hline
\end{tabular}

HIF-1 $\alpha$, hypoxia inducible factor-1 $\alpha$; ZEB1, zinc-finger E-box-binding homeobox 1 .

A

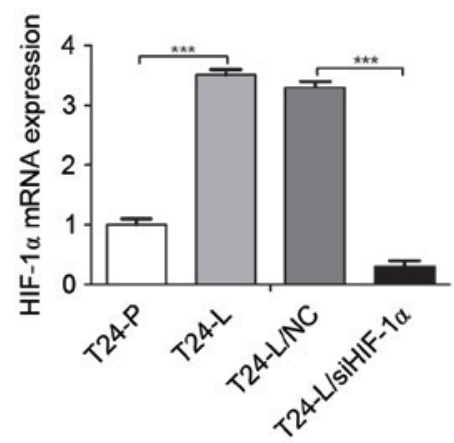

B

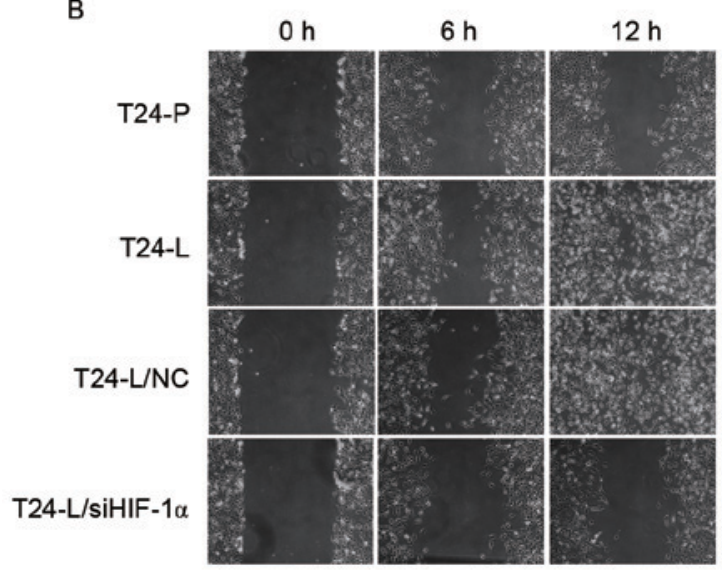

C

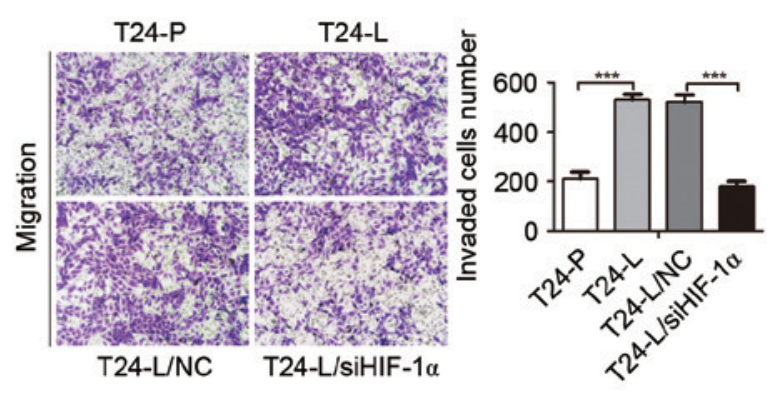

D
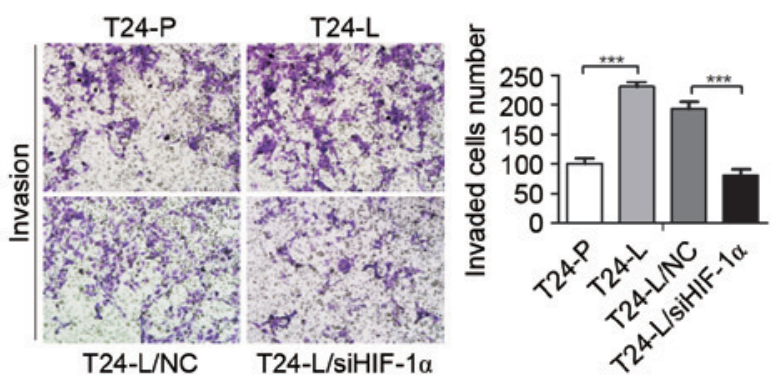

Figure 2. Knockdown of HIF-1 $\alpha$ by siRNA reduces the malignancy of T24-L cells. (A) Reverse transcriptase-quantitative polymerase chain reaction was used to demonstrate the expression of HIF-1 $\alpha$ in T24-L and T24-P, and the efficiency of siRNA against HIF-1 $\alpha$ in T24-L. The expression of HIF-1 $\alpha$ is significantly increased in T24-L. ${ }^{* * *} \mathrm{P}<0.001$ si HIF-1 $\alpha$ vs. NC. (B) Wound-healing assay to demonstrate that T24-L cells exhibited higher migration activity than T24-P cells, and T24-L control cells exhibited higher migration activity compared with HIF-1 $\alpha$ knockdown T24-L cells. Boyden chamber assays to demonstrate that (C) the migration and (D) the migration and invasion ability of T24-L cells was greater compared with T24-P cells, and that HIF-1 $\alpha$ knockdown impaired the migration and invasion capacity of T24-L cells. Magnification, x100. ${ }^{* * *} \mathrm{P}<0.001$. HIF-1 $\alpha$, hypoxia inducible factor-1 $\alpha$; siRNA, small interfering RNA; T24-L, T24 lung metastasis cells; T24-P, T24 parental cells; NC, negative control. 

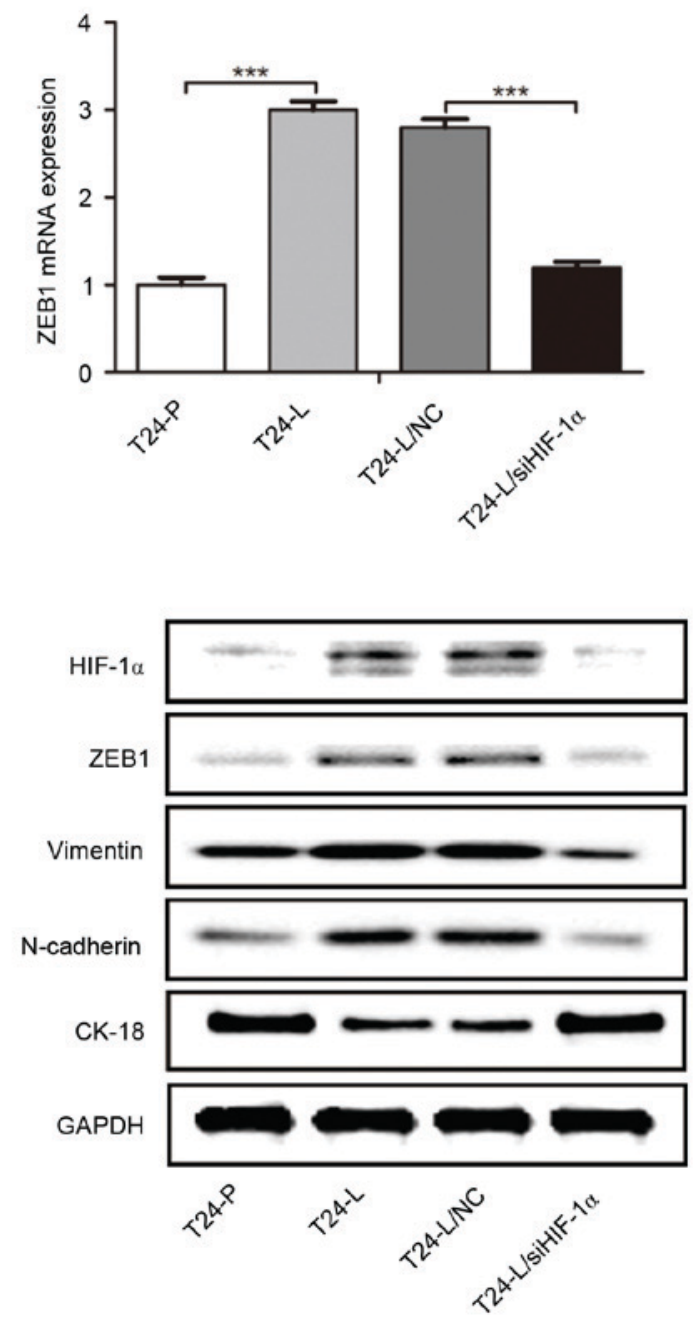

Figure 3. ZEB1 expression is regulated by HIF-1 $\alpha$, and promotes epithelial-mesenchymal transition. (A) Reverse transcription-quantitative polymerase chain reaction was used to determine the level of ZEB1 mRNA expression in T24-P/T24-L/T24-NC/T24-L/siHIF-1 $\alpha$. ZEB1 was significantly elevated in T24-L, and transfection with siHIF-1 $\alpha$ downregulated ZEB1 expression in T24-L cells, compared with the control. (B) Western blot analysis indicated that the protein level of HIF-1 $\alpha$, ZEB1, vimentin and N-cadherin was higher in T24-L cells than T24-P cells, whereas CK-18 expression was lower in T24-L cells. siHIF-1 $\alpha$ transfection in T24-L led to the downregulation of ZEB1, Vimentin and $\mathrm{N}$-Cadherin, but the upregulation of CK-18. ${ }^{* * *} \mathrm{P}<0.001$. ZEB1, zinc-finger E-box-binding homeobox 1; HIF-1 $\alpha$, hypoxia inducible factor-1 $\alpha$; T24-L, T24 lung metastasis cells; siHIF-1 $\alpha$, small interfering RNA against HIF-1 $\alpha$; T24-P, T24 parental cells; CK-18, cytokeratin-18; $\mathrm{NC}$, negative control.

abilities than orthotopic T24-P cells in vitro; the T24-L subline acquired more mesenchymal-like characteristics and the T24-P subline was more epithelial-like.

Consistently, in the present study, HIF-1 $\alpha$, ZEB1, vimentin, and $\mathrm{N}$-cadherin expression were higher, but cytokeratin-18 expression was lower in T24-L cells compared with T24-P cells. Furthermore, knockdown endogenous HIF-1 $\alpha$ expression significantly downregulated the expression of ZEB1, accompanied with a decrease in invasive and metastatic ability in vitro and EMT-related protein changes in T24-L cells. When T24-P cells were cultured under hypoxic conditions, HIF-1 $\alpha$ expression was induced responsively; meanwhile, simultaneously, the expression level of ZEB1, N-cadherin, and
A

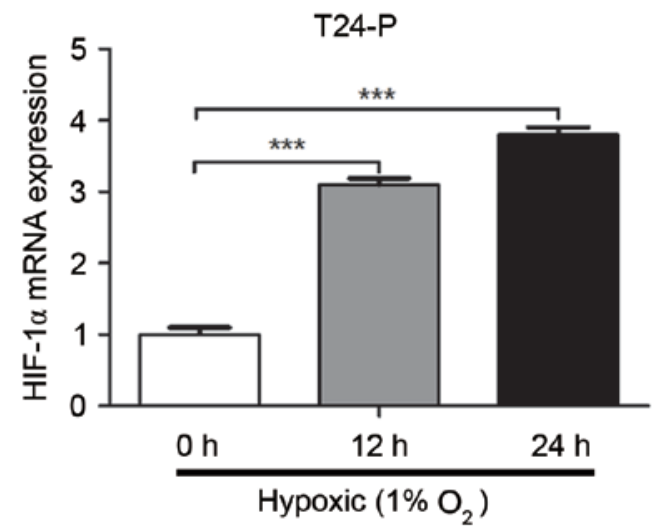

B

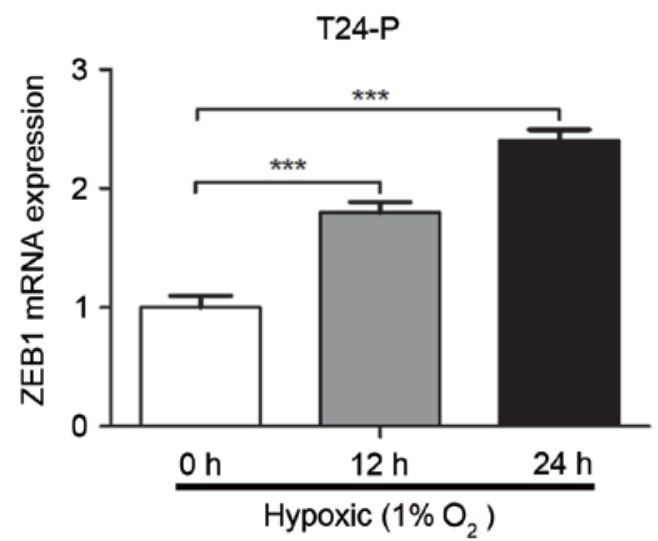

C

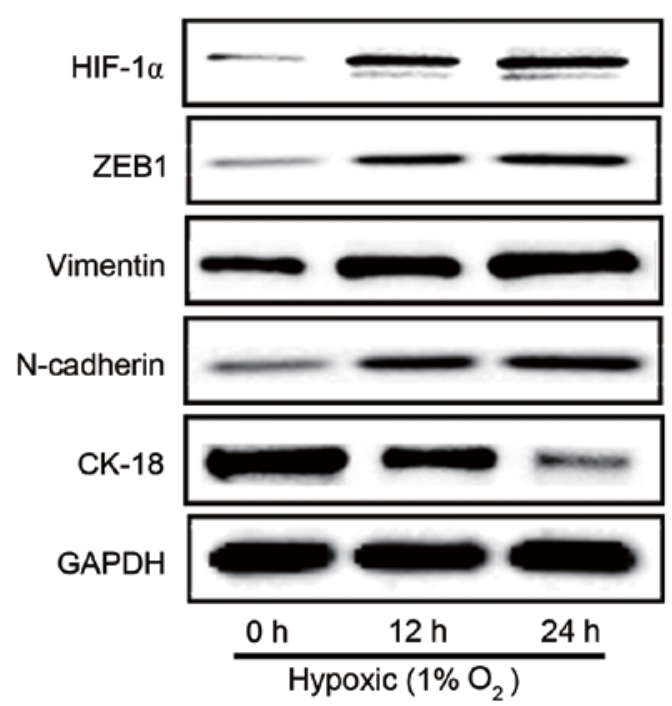

Figure 4. Hypoxia increases the expression of HIF-1 $\alpha$ and ZEB1 in T24-P cells, and promotes the process of epithelial-mesenchymal transition. Induced hypoxia increased the expression of (A) HIF-1 $\alpha$ and (B) ZEB1 in T24-P cells. (C) Western blotting revealed that HIF-1 $\alpha$, ZEB1, N-cadherin and vimentin were upregulated when T24-P cells were grown in hypoxic conditions, but that CK-18 was downregulated. ${ }^{* * *} \mathrm{P}<0.001$. HIF-1 $\alpha$, hypoxia inducible factor-1 $\alpha$; ZEB1, zinc-finger E-box-binding homeobox 1; T24-P, T24 parental cells; CK-18, cytokeratin-18.

vimentin increased, and the expression level of cytokeratin 18 decreased. The data from the present study suggests that the promotion of EMT by HIF-1 $\alpha$-mediated induction of ZEB1 may serve a crucial role in the process of lung metastasis. 
In the present study, it was identified that the expression of HIF-1 $\alpha$ and ZEB1 were associated with each other in bladder cancer tissue. Furthermore, HIF-1 $\alpha$ expression increased the expression of ZEB1 and promoted EMT, cell migration and invasion in a bladder cancer cell spontaneous lung metastases model. These results indicate that HIF-1 $\alpha$ serves an important role in the metastasis of bladder cancer, and that HIF-1 $\alpha$ and ZEB1 may be potential targets for inhibiting bladder metastasis in the future.

\section{Acknowledgements}

The present study was supported by grants from the National Natural Science Foundation of China (grant no. 81572520), the Key Science and Technology Program of Shaanxi Province, China (grant no. 2015SF176), and the Long-term Scheduled Medical Student Research Fund (grant no. 15YB05; The First Affiliated Hospital of Xi'an Jiaotong University, Xi'an, Shaanxi).

\section{References}

1. Jemal A, Siegel R, Xu J and Ward E: Cancer statistics, 2010. CA Cancer J Clin 60: 277-300, 2010.

2. Raghavan D, Shipley WU, Garnick MB, Russell PJ and Richie JP: Biology and management of bladder cancer. N Engl J Med 322: 1129-1138, 1990.

3. Stenzl A, Cowan NC, De Santis M, Jakse G, Kuczyk MA, Merseburger AS, Ribal MJ, Sherif A and Witjes JA: The updated EAU guidelines on muscle-invasive and metastatic bladder cancer. Eur Urol 55: 815-825, 2009.

4. Kurian A, Lee J and Born A: Urothelial bladder cancer with cavitary lung metastases. Can Respir J 18: e46-e47, 2011.

5. Hill RP, Marie-Egyptienne DT and Hedley DW: Cancer stem cells, hypoxia and metastasis. Semin Radiat Oncol 19: 106-111, 2009.

6. Adams JM, Difazio LT, Rolandelli RH, Luján JJ, Haskó G, Csóka B, Selmeczy Z and Németh ZH: HIF-1: A key mediator in hypoxia. Acta Physiol Hung 96: 19-28, 2009.

7. Joseph JV, Conroy S, Pavlov K, Sontakke P, Tomar T, Eggens-Meijer E, Balasubramaniyan V, Wagemakers M, den Dunnen WF and Kruyt FA: Hypoxia enhances migration and invasion in glioblastoma by promoting a mesenchymal shift mediated by the HIF1 $\alpha$-ZEB1 axis. Cancer Lett 359: 107-116, 2015.

8. Wu K, Ning Z, Zeng J, Fan J, Zhou J, Zhang T, Zhang L, Chen Y, Gao Y, Wang B, et al: Silibinin inhibits $\beta$-catenin/ZEB1 signaling and suppresses bladder cancer metastasis via dual-blocking epithelial-mesenchymal transition and stemness. Cell Signal 25: 2625-2633, 2013.

9. Kenney PA, Wszolek MF, Rieger-Christ KM, Neto BS, Gould JJ, Harty NJ, Mosquera JM, Zeheb R, Loda M, Darling DS, et al: Novel ZEB1 expression in bladder tumorigenesis. BJU Int 107: 656-663, 2011.
10. Zhang T, Fan J, Wu K, Zeng J, Sun K, Guan Z, Wang X, Hiesh JT and He D: Roles of HIF-1 $\alpha$ in a novel optical orthotopic spontaneous metastatic bladder cancer animal model. Urol Oncol 30: 928-935, 2012.

11. Karam JA, Huang S, Fan J, Stanfield J, Schultz RA, Pong RC, Sun X, Mason RP, Xie XJ, Niu G, et al: Upregulation of TRAG3 gene in urothelial carcinoma of the bladder. Int $J$ Cancer 128: 2823-2832, 2011.

12. Witjes JA, Compérat E, Cowan NC, De Santis M, Gakis G, Lebret T, Ribal MJ, Van der Heijden AG and Sherif A; European Association of Urology: EAU guidelines on muscle-invasive and metastatic bladder cancer: Summary of the 2013 guidelines. Eur Urol 65: 778-792, 2014.

13. Schned AR, Andrew AS, Marsit CJ, Kelsey KT, Zens MS and Karagas MR: Histological classification and stage of newly diagnosed bladder cancer in a population-based study from the Northeastern United States. Scand J Urol Nephrol 42: 237-242, 2008.

14. Murai T, Yamada S, Fuchs BC, Fujii T, Nakayama G, Sugimoto H, Koike M, Fujiwara M, Tanabe KK and Kodera Y: Epithelial-to-mesenchymal transition predicts prognosis in clinical gastric cancer. J Surg Oncol 109: 684-689, 2014.

15. Pouysségur J, Dayan F and Mazure NM: Hypoxia signalling in cancer and approaches to enforce tumour regression. Nature 441: 437-443, 2006

16. Denko NC: Hypoxia, HIF1 and glucose metabolism in the solid tumour. Nat Rev Cancer 8: 705-713, 2008.

17. Krishnamachary B, Zagzag D, Nagasawa H, Rainey $K$, Okuyama H, Baek JH and Semenza GL: Hypoxia-inducible factor-1-dependent repression of E-cadherin in von Hippel-Lindau tumor suppressor-null renal cell carcinoma mediated by TCF3, ZFHX1A, and ZFHX1B. Cancer Res 66: 2725-2731, 2006.

18. Rohwer N, Lobitz S, Daskalow K, Jöns T, Vieth M, Schlag PM, Kemmner W, Wiedenmann B, Cramer T and Höcker M: HIF-1alpha determines the metastatic potential of gastric cancer cells. Br J Cancer 100: 772-781, 2009.

19. Deniz H, Karakök M, Yagci F and Güldür ME: Evaluation of relationship between HIF-1alpha immunoreactivity and stage, grade, angiogenic profile and proliferative index in bladder urothelial carcinomas. Int Urol Nephrol 42: 103-107, 2010.

20. Meng X, Kong DH, Li N, Zong ZH, Liu BQ, Du ZX, Guan Y, Cao L and Wang HQ: Knockdown of BAG3 induces epithelial-mesenchymal transition in thyroid cancer cells through ZEB1 activation. Cell Death Dis 5: e1092, 2014.

21. Wu K, Fan J, Zhang L, Ning Z, Zeng J, Zhou J, Li L, Chen Y, Zhang $\mathrm{T}$, Wang $\mathrm{X}$, et al: PI3K/Akt to GSK $3 \beta / \beta$-catenin signaling cascade coordinates cell colonization for bladder cancer bone metastasis through regulating ZEB1 transcription. Cell Signal 24: 2273-2282, 2012.

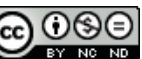

This work is licensed under a Creative Commons Attribution-NonCommercial-NoDerivatives 4.0 International (CC BY-NC-ND 4.0) License. 